\title{
Detrimental effects of coronary stenting on subsequent coronary artery bypass surgery: Is there another flag on the field?
}

\author{
Harold L. Lazar, MD
}

See related article on page 316 .

Twenty-five years ago, Claude Grondin, a pioneer in the development of coronary artery bypass grafting (CABG), wrote an editorial in this Journal entitled "Late Results of Coronary Artery Grafting: Is There a Flag on the Field?"1 In that editorial, Grondin noted that long-term patencies of saphenous vein grafts were significantly reduced as a consequence of recurrent atherosclerotic disease. This observation heralded the emergence of alternative percutaneous methods to treat ischemic heart disease. The cardiac surgeon is now faced with an increasing number of patients with multivessel disease in whom previous percutaneous coronary interventions (PCIs) with coronary stents have already been performed before CABG. In this edition of the Journal, Tran and coworkers ${ }^{2}$ now report that patients with diabetes mellitus who have undergone stenting before CABG face an increased risk of operative death, increased perioperative complications, and decreased long-term survival. Does coronary stenting predispose toward adverse outcomes when CABG is subsequently needed? Is there another flag on the field?

Previous studies have shown the superiority of CABG relative to PCI in patients with diabetes and multivessel disease. ${ }^{3}$ With the advent of the drug-eluting stent (DES), it has been suggested that stents will supplant CABG and become the primary method of revascularization for patients with diabetes mellitus. ${ }^{4}$ The endovascular changes seen in diabetes mellitus, however, increase stent stenosis by accelerating neointimal hyperplasia. ${ }^{5}$ Placing a foreign body, such as a stent, in a coronary artery initiates an inflammatory response that activates platelets and macrophages. This leads to remodeling of the extracellular matrix and smooth muscle migration, which ultimately result in luminal narrowing. ${ }^{6} \mathrm{Al}-$ though DES use has been shown to decrease vascular smooth muscle proliferation and reduce restenosis, the rate of restenosis in patients with diabetes mellitus who receive DES

From the Department of Cardiothoracic Surgery, the Boston Medical Center, and the Boston University School of Medicine, Boston, Mass.

Received for publication April 7, 2009; accepted for publication April 11, 2009.

Address for reprints: Harold L. Lazar, MD, Department of Cardiothoracic Surgery, Boston Medical Center, 88 E Newton St, Boston, MA 02118 (E-mail: harold. lazar@bmc.org).

J Thorac Cardiovasc Surg 2009;138:276-7

$0022-5223 / \$ 36.00$

Copyright (c) 2009 by The American Association for Thoracic Surgery doi: $10.1016 /$ j.jtcvs.2009.04.012 treatment is still significantly greater than that in patients without diabetes mellitus who receive this treatment. ${ }^{7,8}$ In fact, the overall risk for stent thrombosis may be longer for a DES than for a bare metal stent because of the slower rate of re-endothelialization seen with the DES. ${ }^{9}$

In Tran and coworker's series, ${ }^{2}$ patients with previous PCI who underwent CABG had a significantly higher operative mortality ( $2.7 \%$ vs $1.0 \%)$, an increased risk of major adverse cardiac events (MACEs), and a worse age-adjusted survival at 2 -year follow-up $(93.4 \%$ vs $87.4 \% ; P<.017)$. There are, however, certain limitations inherent in the database. The use of statin therapy in both groups was especially low $(<40 \%)$. The overall incidence of MACEs might have been lowered had both groups received statins before CABG. We also are not told whether the vessel that had received a stent was bypassed and whether future ischemic events could have been due to inadequate revascularization of previously stented vessels. The incidences of type 1 diabetes in both groups are not documented, nor are the causes of late deaths. Patients with diabetes mellitus, especially those with type 1 disease, have higher incidences of cerebrovascular, renovascular, and peripheral vascular disease, which could have accounted for the difference in longterm survival. The type of stent used (DES vs bare metal stent), the need for repeated revascularization, and the incidence of vein graft stenosis are also not reported. The mechanism for the decreased long-term survival in the CABG after PCI group is thus unknown. Nevertheless, the data reported by Tran and coworkers ${ }^{2}$ has been documented in other studies involving patients undergoing CABG after previous PCIs. Thielman and coworkers ${ }^{10}$ found that patients with diabetes and multiple-vessel disease who underwent PCI before CABG had higher risks of perioperative death and MACEs. Gaudino and coworkers ${ }^{11}$ found that 5 years after CABG, patients with a previous PCI had a lower saphenous vein graft patency rate $(45 \%$ vs $76.5 \%, P<.0001)$ and a higher incidence of ischemia and recatheterization. Bonaros and coworkers $^{12}$ also noted that patients who had undergone previous PCI before CABG had increased operative mortality and MACE rate, required more blood products, had more bleeding complications, and had a higher incidence of renal failure requiring dialysis. In a multicenter analysis of 37,140 patients undergoing $\mathrm{CABG}$, Massoudy and coworkers ${ }^{13}$ found that multiple previous PCIs significantly increased hospital mortality and MACE rate.

What are the reasons for the increased morbidity and mortality observed in patients who undergo CABG after a previous PCI? Although the exact mechanisms are 
unknown, there are several possible explanations. Patients with previous PCI require antiplatelet agents, which predispose toward increased blood product use and blood loss. Stents not only may result in local vascular inflammation but may stimulate platelet and neutrophil adhesion along the entire vessel, with resulting decreased graft patency. Because of the physical presence of the stent, bypass grafts may need to be inserted more distally in vessels, which may compromise runoff and ultimately patency. Finally, as noted by Tran and coworkers, ${ }^{2}$ patients undergoing CABG after PCI represent a cohort with more advanced atherosclerotic disease, which is associated with reduced graft patency and recurrent ischemic events.

PCI with DESs is now being performed more often in patients with diabetes and multivessel disease. If this trend continues, perioperative and long-term results of $\mathrm{CABG}$ in patients with previous PCI may not be as good as previously reported. The long-term effects of DES use on vascular healing and remodeling remain unknown. It is, however, well known that stents are prone to stenosis and thrombosis. Will they also predispose toward less optimal outcomes after CABG? Our medical colleagues should be alerted to the fact that stenting for multiple-vessel disease may result in increased morbidity and mortality after later CABG. I agree that the Society of Thoracic Surgeons risk model should include all previous PCIs as a risk factor, and not just those performed within 6 hours before surgery. Furthermore, our own surgical colleagues may wish to curb their enthusiasm for hybrid CABG procedures that subject patients to multivessel stenting so that they can perform a minimally invasive left internal thoracic artery to left anterior descending coronary artery anastomosis. It may come back to haunt them when reoperative $\mathrm{CABG}$ is required. Twenty-five years after Grondin's landmark editorial, we must now ask the question, do stents compromise the benefits of CABG surgery? Is there now another flag on the field?

\section{References}

1. Grondin CM. Late results of coronary artery grafting: is there a flag on the field? J Thorac Cardiovasc Surg. 1984;87:161-6.

2. Tran HA, Barnett SD, Hunt SL, Chon A, Ad N. The impact of previous coronary stenting on short- and intermediate-term outcomes following surgical revascularization in patients with diabetes mellitus. J Thorac Cardiovasc Surg. 2009;138: 316-23.

3. Bypass Angioplasty Revascularization Investigation (BARI) Investigators Comparison of coronary bypass surgery with angioplasty in patients with multivessel disease. $N$ Engl J Med. 1996;335:217-25. Erratum in: $N$ Engl J Med. 1997;336:147

4. Van Belle E, Bauters C, Hubert E, Bodart JC, Abolmaali K, Meurice T, et al Restenosis rates in diabetic patients: A comparison of coronary stenting and balloon angioplasty in native coronary vessels. Circulation. 1997;96:1454-60.

5. Flaherty JD, Davidson CJ. Diabetes and coronary revascularization. JAMA. 2005; 293:1501-8.

6. Sousa JE, Serruys PW, Costa MA. New frontiers in cardiology: drug-eluting stents: Part I. Circulation. 2003;107:2274-9.

7. Scheen AJ, Warzée F, Legrand VM. Drug-eluting stents: meta-analysis in diabetic patients. Eur Heart J. 2004;25:2167-8.

8. Schampaert E, Cohen EA, Schlüter M, Reeves F, Trabousli M, Title LM, et al. The Canadian study of the sirolimus-eluting stent in the treatment of patients with long de novo lesions in small native coronary arteries (C-SIRIUS). $J$ Am Coll Cardiol. 2004;43:1110-5.

9. Guagliomi G, Farb A, Musumeci G, Valsecchi O, Tespili M, Motta T, et al. Images in cardiovascular medicine, sirolimus-eluting stent implanted in human coronary artery for 16 months: pathological findings. Circulation. 2003;107:1340-1

10. Thielmann M, Neuhäuser M, Knip S, Kottenberg-Assenmacher E, Marr A Pizanis M, et al. Prognostic impact of previous percutaneous coronary intervention in patients with diabetes mellitus and triple-vessel disease undergoing coronary artery bypass surgery. J Thorac Cardiovasc Surg. 2007;134:470-6.

11. Guadino M, Luciani N, Glieca F, Cellini C, Pragliola C, Trani C, et al. Patient with in-stent restenosis have an increased risk of mid-term venous graft failure. Ann Thorac Surg. 2006;82:802-4.

12. Bongros N, Hennerbichler D, Friedrich G, Kocher A, Pachinger O, Laufer G, et al Increased mortality and perioperative complications in patients with previous elective percutaneous coronary interventions undergoing coronary artery bypass surgery. J Thorac Cardiovasc Surg. 2009;137:846-52.

13. Massoudy P, Thielmann M, Lehmann N, Marr A, Kleikamp G, Maleszka A, et al. Impact of prior percutaneous coronary intervention on the outcome of coronary artery bypass surgery: a multicenter analysis. J Thorac Cardiovasc Surg. 2009;137:840-5. 